\title{
Can baseline serum creatinine and e-GFR predict renal function outcome after augmentation cystoplasty in children?
}

\author{
Prempal Singh ${ }^{1}$, Ankur Bansal ${ }^{1}$, Virender Sekhon ${ }^{1}$, Sandeep Nunia ${ }^{1}$, M. S. Ansari ${ }^{1}$ \\ ${ }^{1}$ Department of Urology and Renal Transplant, Sanjay Gandhi Postgraduate Institute of Medical Sciences, \\ Lucknow, India
}

\section{ABSTRACT}

Objective: To assess cut-off value of creatinine and glomerular filtration rate for augmentation cystoplasty (AC) in paediatric age-group.

Materials and Methods: Data of all paediatric-patients ( $<18$ years) with small capacity bladder, in whom AC was advised between 2005-2015 were reviewed. All patients were divided in two-groups, AC-group and control-group (without AC). Creatinine and e-GFR were assessed at the time of surgery, at 6 months and at last follow-up. Renal function deterioration was defined as increase in creatinine by $\geq 25 \%$ from baseline value or new-onset stage-3 CKD or worsening of CKD stage with pre-operative-CKD stage-3. ROCs were plotted using creatinine and e-GFR for AC.

Results: A total of 94 patients with mean-age 8.9 years were included. The mean creatinine and e-GFR were $1.33 \mathrm{mg} / \mathrm{dL}$ and $57.68 \mathrm{~mL} / \mathrm{min}$ respectively. Out of 94 patients, $\mathrm{AC}$ was performed in 45 patients and in the remaining 49 patients $\mathrm{AC}$ was not done (control-group), as they were not willing for the same. Baseline patient's characteristics were comparable in both Groups. 22 underwent gastro-cystoplasty (GC) and 25 underwent ileo-cystoplasty (IC). Decline in renal function was observed in 15 (33.3\%) patients of AC-group and in 31 (63.3\%) patients of control-group. Patients having creatinine $\geq 1.54 \mathrm{mg} / \mathrm{dL}$ ( $\mathrm{P}=0.004$, sensitivity (S) 63.6\% and specificity (s) 90.5\%) at baseline and e-GFR $\leq 46 \mathrm{~mL} / \mathrm{min}(\mathrm{P}=0.000, \mathrm{~S}=100 \%$ and $\mathrm{s}=85.7 \%)$ at the time of surgery had significantly increased probability of renal function deterioration on follow-up after AC.

Conclusion: e-GFR $\leq 46 \mathrm{~mL} / \mathrm{min}$ and creatinine $\geq 1.54 \mathrm{mg} / \mathrm{dL}$ at time of surgery could serve as a predictor of renal function deterioration in $\mathrm{AC}$ in paediatric patients.

\section{ARTICLE INFO}

\section{Keywords:}

Serum; Delayed Graft Function; Creatinine

Int Braz J Urol. 2018; 44: 156-62

Submitted for publication:

February 11, 2017

Accepted after revision:

March 08, 2017

Published as Ahead of Print: June 28, 2017

\section{INTRODUCTION}

Augmentation cystoplasty $[\mathrm{AC}]$ is one of the major reconstructive surgeries performed in paediatric patients. Augmentation cystoplasty including gastro-cystoplasty and ileo-cystoplasty preserves renal function and provides urinary continence in most children with intractable lo- wer urinary tract disease. Use of augmentation cystoplasty has decreased in developed countries like UK and USA in recent years $(1,2)$, however in many developing countries it is still one of the commonly performed surgeries in children. It may be due to relatively high prevalence of tuberculosis/parasitic infection and neglected congenital malformation in developing countries. Indications 
for augmentation cystoplasty include bladder capacity $\leq 65 \%$ of age, end filling pressures $>40 \mathrm{~cm}$ of water, intractable irritative lower urinary tract symptoms in spite of anticholinergics. Despite successful augmentation cystoplasty, many of these children progress to chronic kidney disease (CKD).

The reported long term outcomes following AC vary widely among different studies including decline in renal function, pyelonephritis, spontaneous bladder perforation, bladder calculi, and increased risk of malignancy following $\mathrm{AC}$ (3-7). Despite successful surgery, some of these children continue to have fall in renal function. Only few studies have reported on decline in renal function after augmentation cystoplasty, with higher incidence in lower urinary tract obstruction (8). However, none of the studies documented the association of baseline renal function and development of subsequent CKD after augmentation cystoplasty.

\section{MATERIALS AND METHODS}

Data of all paediatric patients with small capacity bladder, in whom augmentation cystoplasty (AC) was advised between January 2005 to December 2015, were reviewed. All patients were divided in two Groups, augmentation cystoplasty Group (AC Group) who underwent AC and control Goup, in whom augmentation of bladder was not done. Glomerular filtration rate (e-GFR) was calculated using the Schwartz equation. Serum creatinine and e-GFR were assessed in AC Group at the time of surgery, then at 6 months and at last follow-up and in control Group at baseline, then at 6 months and at last follow-up. Renal function deterioration was defined as increase in serum creatinine by $25 \%$ or more than the base line value or new-onset stage- 3 chronic kidney disease (CKD) or worsening of CKD stage with pre-operative CKD stage-3. Receiver Operator Curves (ROC) were plotted using serum creatinine and e-GFR for augmentation cystoplasty.

\section{RESULTS}

94 patients with mean age 8.9 years (range 6 to 17 years) were included. Among 94 patients,
56 were boys and 38 were girls. The mean serum creatinine and e-GFR were $1.33 \mathrm{mg} / \mathrm{dL}$ (range 0.4 to $2.4 \mathrm{mg} / \mathrm{dL}$ ) and $57.68 \mathrm{~mL} / \mathrm{min}$ (range 28 to $82 \mathrm{~mL} / \mathrm{min}$ ) respectively. Out of 94 patients, augmentation cystoplasty was performed in 45 patients (AC Group) and in the remaining 49 patients augmentation cystoplasty was not done (Control Group), as they were not willing for the same. Baseline patient's characteristics were comparable in both the groups (Table-1).

In AC Group, ileo-cystoplasty (IC) was done in 25 patients and 20 patients underwent gastro-cystoplasty (GC) as per patient's characteristics (Tables 2 and 3). Gastro-cystoplasty was performed in two-third male patients because of chronic kidney disease due to posterior urethral valve (PUV). Ileo-cystoplasty was performed in all thirteen patients with exstrophy/epispadias reconstruction. No posterior urethral valve patient underwent IC due to raised serum creatinine at the time of augmentation cystoplasty. Baseline mean serum creatinine was $1.30 \mathrm{mg} / \mathrm{dL}$ and $1.35 \mathrm{mg} / \mathrm{dL}$ in IC and GC Group respectively, while baseline mean e-GFR was $74 \mathrm{~mL} / \mathrm{min}$ and $39.75 \mathrm{~mL} / \mathrm{min}$. Out of 94 patients, 52 had baseline chronic kidney disease (CKD) [46 patients had chronic kidney disease stage III and 6 had chronic kidney disease stage IV]. Among these 52 patients with baseline CKD, 25 patients were in AC Group and remaining 27 patients were in control Group. Gastro-cystoplasty was performed in 18 patients with chronic kidney disease (15 were in CKD stage III and all CKD stage IV) and ileo-cystoplasty was performed in 7 patients with CKD stage III.

Decline in renal function was observed in 15 (33.3\%) patients of AC Group and in 31 (61.3\%) patients of control Group, which was significantly higher in control Group ( $p$ value: 0.004). Out of 15 patients with declined renal function in $\mathrm{AC}$ Group, 12 (60\%) patients were in GC Group and $3(12 \%)$ patients were in IC Group, maybe because $90 \%$ of GC Group patients had baseline CKD. Among these 12 patients in GC Group, 9 patients had baseline CKD stage III B and 3 had baseline CKD stage IV. Three patients who had deterioration of renal function in IC Group, had baseline CKD III B stage. The mean baseline e-GFR were 40 and $29.22 \mathrm{~mL} / \mathrm{min}$ in IC and GC Group respec- 
Table 1 - Patient Characteristics.

\begin{tabular}{|c|c|c|c|}
\hline Patients Characteristics & $\begin{array}{c}\text { Augmentation } \\
\text { Cystoplasty }\end{array}$ & Control group & $P$ value \\
\hline No of Patients & 45 & 49 & \\
\hline Mean Age (Range) & $9.34(5-17)$ & $8.57(6-16)$ & 0.8 \\
\hline \multicolumn{4}{|l|}{ Gender } \\
\hline Boys & 27 & 29 & 1.0 \\
\hline Girl & 18 & 20 & \\
\hline \multicolumn{4}{|l|}{ Diagnosis } \\
\hline PUV & 19 & 23 & \\
\hline Neurogenic Bladder & 08 & 20 & \\
\hline Extrophy Bladder & 07 & 00 & 0.68 \\
\hline Epispadias & 06 & 04 & \\
\hline GUTB & 05 & 02 & \\
\hline Mean Baseline e-GFR (mL/min.) & $58.73 \pm 21.8$ & $56.72 \pm 19.5$ & 0.63 \\
\hline \multicolumn{4}{|l|}{ Baseline renal function } \\
\hline Stage $0-\|$ & 20 & 22 & 1.0 \\
\hline Stage III- V & 25 & 27 & \\
\hline Mean Baseline Serum Creatinine (mg/dL) & $1.32 \pm 0.8$ & $1.34 \pm 1.1$ & 0.92 \\
\hline \multicolumn{4}{|l|}{ Renal function outcome $(\mathrm{N}, \%)$} \\
\hline Decline & $15(33.3 \%)$ & $31(63.3 \%)$ & 0.004 \\
\hline Stable & $30(66.7 \%)$ & $18(36.7 \%)$ & \\
\hline Mean e-GFR at last follow-up (mL/min.) & $55.72 \pm 18.4$ & $42.8 \pm 16.5$ & 0.001 \\
\hline Mean Serum Creatinine at last follow-up (mg/dL) & $1.34 \pm 0.7$ & $1.69 \pm 0.8$ & 0.026 \\
\hline
\end{tabular}

tively in patients, who had deterioration in renal function after augmentation cystoplasty. However, stable renal function was observed after 5.7 years of mean follow-up in $30(66.7 \%)$ patients of AC Group and in 18 (36.7\%) patients of control Group, which was significantly lower in control Group (p value: 0.004 ).

Mean e-GFR at last follow-up in AC and control Group was $55.7 \mathrm{~mL} / \mathrm{min}$ and $42.8 \mathrm{~mL} / \mathrm{min}$ respectively, which was significantly lower in control Group (p value: 0.001).

Similarly, mean serum creatinine at last follow-up in AC and control Group was $1.34 \mathrm{mg} /$ $\mathrm{dL}$ and $1.69 \mathrm{mg} / \mathrm{dL}$, which was also significantly higher in control Group (p value: 0.026). Receiver
Operator Curves (ROC) were plotted using serum creatinine and e-GFR. Patients having serum creatinine $\geq 1.54 \mathrm{mg} / \mathrm{dL}$ (Figure-1) and e-GFR $\leq 4 \mathrm{~mL}$ / min (Figure-2) at time of surgery had significantly increased probability of renal function deterioration with sensitivity 63.6\% and specificity 90.5\% $(\mathrm{p}=0.004)$ and sensitivity $100 \%$ and specificity 85.7\% ( $\mathrm{p}=0.00)$ respectively on follow-up after AC.

\section{DISCUSSION}

The major goals of augmentation cystoplasty are to provide a compliant bladder with low end filling pressure, increase bladder capacity and or control bladder over activity. AC should allow 
Table 2 - Baseline Renal Function and Underlying Pathology (AC group/ Control group).

\begin{tabular}{lccccccc}
\hline Underlying & $\begin{array}{c}\text { No Of } \\
\text { Patients }\end{array}$ & $\begin{array}{c}\text { CKD } \\
\text { Stage }\end{array}$ & $\begin{array}{c}\text { CKD } \\
\text { Stage }\end{array}$ & $\begin{array}{c}\text { CKD } \\
\text { Stage }\end{array}$ & $\begin{array}{c}\text { CKD } \\
\text { Stage }\end{array}$ & $\begin{array}{c}\text { CKD } \\
\text { Stage }\end{array}$ & CKD Stage \\
\hline Pathology & & 0 & I & II & III & IV & V \\
PUV (Total) & 42 & & & & & & \\
AC group & 19 & - & - & 05 & 12 & 02 & - \\
Control group & 23 & - & - & 11 & 10 & 02 & - \\
Neurogenic Bladder (Total) & 28 & & & & & & \\
AC group & 08 & - & 01 & 01 & 05 & 01 & - \\
Control group & 20 & 01 & 01 & 05 & 12 & 01 & - \\
Extrophy Bladder (Total) & 07 & & & & & & \\
AC group & 07 & 05 & - & 02 & - & - & - \\
Control group & - & - & - & - & - & - & - \\
Epispadia (Total) & 10 & & & & & & - \\
AC group & 06 & 04 & 02 & - & - & - & - \\
Control group & 04 & 04 & - & - & - & - & - \\
GUTB ( Total ) & 07 & & & & & & - \\
AC group & 05 & - & - & - & 05 & - & - \\
Control group & 02 & - & - & - & 02 & - & - \\
\hline
\end{tabular}

Table 3 - Baseline CKD Stage Distribution In Ileo-cystoplasty And Gastro-cystoplasty.

\begin{tabular}{lccccccc}
\hline Augmentation Cystoplasty & No of Patients & 0 & I & II & III & IV & V \\
\hline Ileocystoplasty & 25 & 12 & 02 & 05 & 07 & - & - \\
Gastrocystoplasty & 20 & - & - & 02 & 15 & 03 & - \\
\hline
\end{tabular}

the upper tracts to remain intact while preserving renal function and maintain urinary continence (9-13) In spite of a worldwide decrease, AC remains an option, with high patient acceptance rates, in both neurogenic and non-neurogenic bladder dysfunction when conservative treatments such as pharmacological methods and minimally invasive treatments like intravesical botulinum have been unsuccessful $(14,15)$.

In various studies the renal function has been reported to improve, remain stable or even worsen after $\mathrm{AC}(8,9-11,16)$. In spite of successful surgery, in some of the children the renal function continues to deteriorate. Most of the studies have described the metabolic complications, only few studies have reported on decline in renal function after AC (17) Further, none of the study documented the association of baseline renal function and development of subsequent CKD after augmentation cystoplasty.

In studies that have shown the fall in renal function, the rate of decline appeared to be 
Figure 1 - Receiver Operator Curve of Baseline Serum Creatinine for Augmentation Cystoplasty.

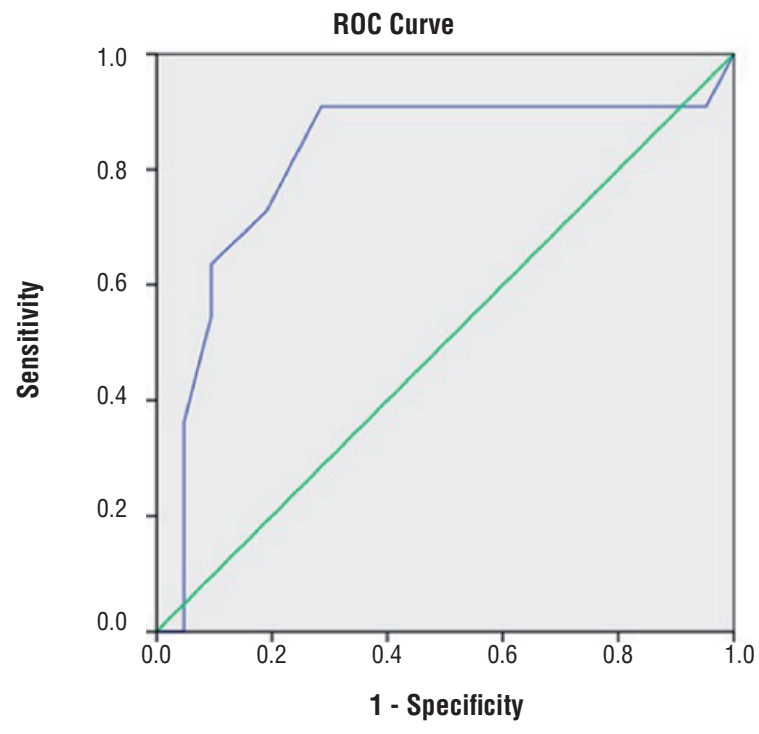

Area Under the Curve

\begin{tabular}{|l|c|c|c|c|}
\hline \multirow{2}{*}{ Area } & \multirow{2}{*}{ Std. Error } & \multirow{2}{*}{$p$ value } & \multicolumn{2}{|c|}{ Asymptotic 95\% Confidence Interval } \\
\cline { 4 - 5 } & & & Lower Bound & Upper Bound \\
\hline .816 & .092 & .004 & .635 & .997 \\
\hline
\end{tabular}

Diagonal segments are produced by ties.

Figure 2 - Receiver Operator Curve of Baseline e-GFR For Augmentation Cystoplasty.

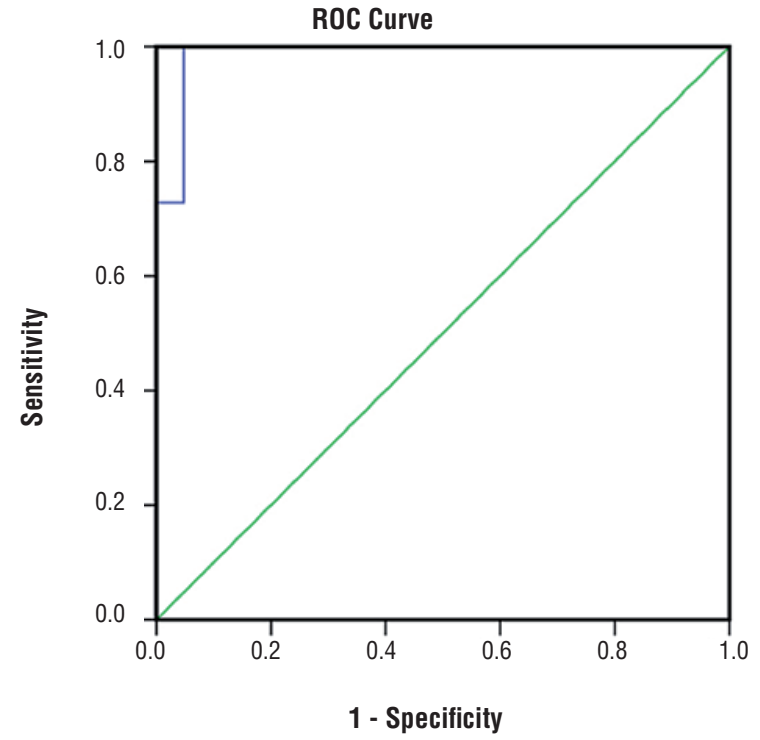

related to the pre-operative creatinine clearance. Kuss et al., found deterioration in only $4.1 \%$ of patients who had a creatinine clearance of $\geq 40 \mathrm{~mL} /$ min (17). In the present study, no patient required dialysis in immediate postoperative period. By 12 months of follow-up, the average increase in se-
Area Under the Curve

\begin{tabular}{|c|c|c|c|c|}
\hline \multicolumn{5}{|c|}{ Test Result Variable(s): gfr0 } \\
\hline \multirow[t]{2}{*}{ Area } & \multirow{2}{*}{ Std. Error ${ }^{a}$} & \multirow[t]{2}{*}{$p$ value } & \multicolumn{2}{|c|}{ Asymptotic $95 \%$ Confidence Interval } \\
\hline & & & Lower Bound & Upper Bound \\
\hline 0.987 & 0.16 & 0.000 & 0.957 & 1.000 \\
\hline
\end{tabular}

rum creatinine was $0.20 \mathrm{mg} / \mathrm{dL}$. It is unclear what was the cause of rise in creatinine in these patients. Possible etiologies could be absorption of creatinine from the intestinal mucosa or inherent progression of baseline chronic kidney disease. These require future studies using more objective mea- 
sures. Even the use of stomach did not appear to be protective for further decline in renal function after $\mathrm{GC}$, if the baseline e-GFR was less than 30 or CKD stage 4. However, mean baseline e-GFR for GC was $39.75 \mathrm{~mL} / \mathrm{min}$, which means most of the patients who underwent GC had CKD at the time surgery and the reasons for post-GC decline in renal function might be further progression of baseline CKD or renal dysplasia (most being the cases of PUV) (18).

Overall, renal function deterioration was observed in 15 patients (33.3\%) of AC Group at mean follow-up of 5.7 years. E. Fontaine et al. showed that lower urinary tract reconstruction was associated with a significant deterioration in renal function in 19\% of patients after 10 years of follow-up (16); this incidence is much lower as compared to the present study, probably on account of the different patient population as they included only exstrophy patients. Congenital renal damage is rare in exstrophy patients before surgical correction, so that renal dysplasia or intrauterine nephropathy can be eliminated as a cause of any subsequent deterioration in renal function (18). In our study, $20(44.4 \%)$ patients of AC Group and 25 (51.0\%) patients of control group had baseline CKD due to lower urinary tract obstruction (LUTO).

Bruce J. Schlomer et al. also demonstrated that principal diagnosis was strongly associated with risk of decline in renal function or CKD after AC. A diagnosis of LUTO including posterior urethral valves (PUV) or neurogenic bladder was strongly associated with subsequent renal function deterioration (HR 13.7, 95\% CI 9.7e19.9) (8). Developing CKD is likely related to primary pathology i.e. LUTO and not caused by augmentation cystoplasty itself (8).

Mean e-GFR of IC Group was $74 \mathrm{~mL} / \mathrm{min}$ and 7 patients had CKD stage III. Out of 07 patients, $03(12 \%)$ patients had further progression of chronic kidney disease and both patients had e-GFR lower than $45 \mathrm{~mL} / \mathrm{min}$ and no hydroureteronephrosis (HDUN) or obstructive uropathy on ultrasonography. Among 20 patients of GC Group, 18 had CKD at the time of surgery with mean e-GFR $39.37 \mathrm{~mL} /$ min. Fifteen patients were in CKD stage III and 3 were in CKD stage IV. Twelve (60\%) patients, who underwent GC showed decline in renal function. All patients with CKD stage IV $(n=3)$ and 9 patients with CKD stage III B in GC Group, noticed deterioration in renal function within one year after $\mathrm{AC}$ with baseline mean e-GFR $29.2 \mathrm{~mL} / \mathrm{min}$. In the present study, it was found that the IC is a safe alternative for the patient who have e-GFR $46 \mathrm{~mL} / \mathrm{min}$ or more. For patients with baseline CKD stage-IIIB, GC is a worthwhile option up to e-GFR $38 \mathrm{~mL} / \mathrm{min}$ or more. Further, renal functional outcome in children after AC are poor, if e-GFR is $46 \mathrm{~mL} / \mathrm{min}$ or lower. Mean baseline serum creatinine in our study was $1.35 \mathrm{mg} \%$ in patients who recorded decline in renal function after AC. Patients who maintained stable renal function after $\mathrm{AC}$ had a mean baseline serum creatinine of $1.2 \mathrm{mg} \%$. Authors acknowledge that this was a retrospective study and serum creatinine is influenced by patient age, sex and lean body mass. Intestinal segments used for augmentation cystoplasty might absorb creatinine from urine, which may result in falsely elevated serum creatinine measurements. More accurate measurement of renal function like cystatin c assessment would be helpful but was unavailable for this retrospective study. Besides, the study includes heterogeneous patients with wide range of diagnosis and baseline renal function. About 55.55\% of patients had baseline chronic kidney disease (CKD stage III and stage IV), who underwent augmentation-cystoplasty. Ninety percent patients with baseline chronic kidney disease underwent GC in an attempt to decrease metabolic complications and stable renal function.

\section{CONCLUSIONS}

Baseline GFR and serum creatinine both can predict the long-term renal outcome. e Glomerular filtration rate $\leq 4 \mathrm{~mL} / \mathrm{min}$ and serum creatinine $1.54 \mathrm{mg} / \mathrm{dL}$ at time of surgery could serve as predictors of renal function deterioration in augmentation cystoplasty in paediatric patients.

\section{ABBREVIATIONS}

$$
\begin{aligned}
& \text { AC = Augmentation cystoplasty } \\
& \text { IC = Ileo-cystoplasty } \\
& \text { GC = Gastro-cystoplasty } \\
& \text { LUTO = Lower urinary tract obstruction } \\
& \text { e-GFR = Estimated Glomerular filtration rate } \\
& \text { (calculated using the Schwartz equation) }
\end{aligned}
$$


CKD $=$ Chronic kidney disease

ROC $=$ Receiver operator characteristic curve

\section{CONFLICT OF INTEREST}

None declared.

\section{REFERENCES}

1. Biers SM, Venn SN, Greenwell TJ. The past, present and future of augmentation cystoplasty. BJU Int. 2012;109:1280-93.

2. Schlomer BJ, Saperston K, Baskin L. National trends in augmentation cystoplasty in the 2000s and factors associated with patient outcomes. J Urol. 2013;190:1352-7.

3. Jørgensen B, Olsen LH, Jørgensen TM. Long-term follow-up in spinal dysraphism: outcome of renal function and urinary and faecal continence. Scand J Urol Nephrol. 2010;44:95-100.

4. Filler G, Gharib M, Casier S, Lödige P, Ehrich JH, Dave S. Prevention of chronic kidney disease in spina bifida. Int Urol Nephrol. 2012;44:817-27.

5. Malakounides G, Lee F, Murphy F, Boddy SA. Single centre experience: long term outcomes in spina bifida patients. J Pediatr Urol. 2013;9:585-9.

6. Husmann DA, Rathbun SR. Long-term follow up of enteric bladder augmentations: the risk for malignancy. J Pediatr Urol. 2008;4:381-5.

7. Higuchi TT, Granberg CF, Fox JA, Husmann DA. Augmentation cystoplasty and risk of neoplasia: fact, fiction and controversy. J Urol. 2010;184:2492-6.

8. Schlomer BJ, Copp HL. Cumulative incidence of outcomes and urologic procedures after augmentation cystoplasty. J Pediatr Urol. 2014;10:1043-50.

9. Akerlund S, Delin K, Kock NG, Lycke G, Philipson BM, Volkmann R. Renal function and upper urinary tract configuration following urinary diversion to a continent ileal reservoir (Kock pouch): a prospective 5 to 11-year followup after reservoir construction. J Urol. 1989;142:964-8.

10. Kristjánsson $A$, Bajc $M$, Wallin L, Willner J, Månsson W. Renal function up to 16 years after conduit (refluxing or anti-reflux anastomosis) or continente urinary diversion. 2. Renal scarring and location of bacteriuria. Br J Urol. 1995;76:546-50.

11. Studer UE, Danuser H, Moehrle K, Mills RD, Thalman GN Results in the upper urinary tract in 220 patients with an ileal low pressure bladder substitute combined with an afferent tubular segment. J Urol 1999; 161 (Suppl 4): A91.

12. Abd-el-Gawad G, Abrahamsson K, Hanson E, Norlén L, Sillén U, Stokland E, et al. Kock urinary reservoir maturation in children and adolescents: consequences for kidney and upper urinary tract. Eur Urol. 1999;36:443-9.

13. Clementson Kockum C, Helin I, Malmberg L, Malmfors G. Pediatric urinary tract reconstruction using intestine. Scand J Urol Nephrol. 1999;33:53-6.

14. Philp NH, Williams JL, Byers CE. Ileal conduit urinary diversion: long-term follow-up in adults. $\mathrm{Br} \mathrm{J}$ Urol. 1980;52:515-9.

15. Clarke BG, Leadbetter WF. Ureterosigmoidostomy: collective review of results in 2897 reported cases. J Urol. 1955;73:999-1008.

16. Fontaine $E$, Leaver $R$, Woodhouse CR. The effect of intestinal urinary reservoirs on renal function: a 10-year follow-up. BJU Int. 2000;86:195-8.

17. Küss R, Bitker M, Camey M, Chatelain C, Lassau JP. Indications and early and late results of intestino-cystoplasty: a review of 185 cases. J Urol. 1970;103:53-63.

18. Turner WR, Ransley PG, Williams DI. Patterns of renal damage in the management of vesical exstrophy. J Urol. 1980;124:412-6.

Correspondence address: M. S. Ansari, MD

Department of Urology and Renal Transplant Sanjay Gandhi Postgraduate Institute of Medical Sciences Lucknow, 226014, India Telephone: 91800 490-4801 E-mail: ansarimsa@hotmail.com 